\title{
APLIKASI WHATSAPP SEBAGAI MEDIA ALTERNATIF UJIAN ONLINE DI SIT MUSH’AB BIN UMAIR
}

\author{
Taufik Barlian, Kiagus Ahmad Roni, Sofiah, Yosi Apriani \\ Fakultas Teknik, Universitas Muhammadiyah Palembang, Indonesia \\ yosi_apriani@um-palembang.ac.id.
}

\begin{abstract}
Distance learning causes teachers to think creatively so that the teaching and learning process continues as it should. Also, various platforms and media for online learning are still not widely known by teachers. The Whatsapp application is an application that is already widely used. In this application, it is possible to form groups that can gather many people to chat with each other and exchange information that allows the delivery of messages in groups besides delivering messages individually. The purpose of this service is so that teachers can make maximum use of Whatsapp media as a distance learning facility. The method in this service of AbdiMas team took the initiative to conduct a one-day coaching clinic using the Whatsapp application to evaluate student learning to SIT Mush'ab bin Umair teachers. This dedication activity concludes that this community service activity is felt to be very beneficial for the SIT Mush'ab bin Umair teachers. In part, the limitations of online learning facilities and infrastructure can be overcome by using Whatsapp. Whatsapp as an online exam means considered relatively cheap with a wide reach, easy to use, especially for most SIT Mush'ab bin Umair students who are still in grades 1 and 2.
\end{abstract}

Keywords: Whatsapp, distance learning, teachers

\begin{abstract}
Abstrak
Pembelajaran secara jarak jauh menyebabkan para guru harus berfikir kreatif agar proses belajar mengajar tetap berjalan sebagaimana mestinya. Selain itu berbagai platform dan media untuk pembelajaran secara daring masih belum banyak belum diketahui oleh para guru. Aplikasi Whatsapp merupkan aplikasi yang sudah banyak digunakan. Pada aplikasi ini memungkinkan untuk dibentuk grup yang dapat mengumpulkan banyak orang untuk dapat saling berbincang dan bertukar informasi yang memungkinkan penyampaian pesan secara berkelompok selain menyampaikan pesan secara per orangan. Tujuan pengabdian ini agar para guru bisa memanfaatkan media Whatsapp dengan maksimal sebagai salah satu fasilitas pembelajaran jarak jauh. Metode dalam pengabdian ini tim AbdiMas berinisiatif melakukan one day coaching clinic pemanfaatan aplikasi Whatsapp sebagai salah satu sarana untuk melakukan evaluasi pembelajaran siswa kepada guru-guru SIT Mush'ab bin Umair. Kesimpulan dari kegiatan pengabdian ini yaitu kegiatan abdimas ini dirasakan amat bermanfaat bagi para guru SIT Mush'ab bin Umair. Keterbatasan sarana dan prasarana pembelajaran online sebagian dapat teratasi dengan penggunaan Whatsapp. Penggunaan Whatsapp sebagai sarana ujian online dirasakan relatif murah dengan jangkauan yang luas, mudah dalam penggunaan terutama bagi sebagian besar siswa SIT Mush'ab bin Umair yang masih duduk di kelas 1 dan 2.
\end{abstract}

Kata kunci: Whatsapp, pembelajaran jarak jauh, guru

MARTABE : Jurnal Pengabdian Masyarakat| 268 


\section{PENDAHULUAN}

Masa pembelajaran daring mulai berlangsung pertengahan semester genap Tahun Ajaran 2019/2020 dan berlangsung hingga semester ganjil Tahun Ajaran 2020/2021 di semua jenjang sekolah. Merebaknya pandemi Covid 19, memaksa aktifitas belajar diselenggarakan secara daring. Kendala yang dihadapi sebagian besar sekolah adalah belum tersedianya Learning Management System yang mengakomodir proses pembelajaran daring ini. Selain itu berbagai platform dan media pembelajaran daring masih banyak belum diketahui oleh para guru. Aplikasi Whatsapp merupakan aplikasi yang sudah banyak digunakan orang. Pada aplikasi ini memungkinkan untuk dibentuk grup yang dapat mengumpulkan banyak orang untuk dapat saling berbincang dan bertukar informasi yang memungkinkan penyampaian pesan secara berkelompok selain menyampaikan pesan secara per orangan.(Suryani, 2010). Hal inilah yang membuat masyarakat banyak kalangan yang memanfaatkan aplikasi termasuk para guru. Whatsapp menjadi sarana komunikasi baik guru dengan orangtua/wali siswa maupun guru dengan siswa. Hal ini juga dilakukan oleh guru-guru di SIT Mush'ab bin Umair Palembang. Melalui Grup WA, guru dapat dengan mudah dan cepat membagikan berbagai informasi menyangkut pelajaran maupun kebijakan-kebijakan

sekolah.(Kartikawati \& Pratama, 2017) Whatsapp menyajikan beberapa fitur yang menarik serta mudah pengoperasiannya. Seperti melampirkan video, foto, file dalam bentuk pdf ataupun word, panggilan suara dan video conference serta mengirimkan pesan suara. Keunggulan lain dari Whatsapp adalah kemudahan dalam penggunaan, jangkauannya luas dan pemakaian kuota data yang minim, sehingga aplikasi ini semakin menarik untuk digunakan.(Sofyana \& Rozaq, 2019),(Suana, Raviany, \& Sesunan, 2019)

Beberapa penelitian menunjukkan pemanfaatan Whatsapp sebagai salah satu sarana pembelajaran online cukup efektif. Sebagai contoh, efektifitas penggunaan Whatsapp pada pembelajaran daring di kelas karyawan Prodi Teknik Informatika Universitas PGRI mencapai 78\%. Bahkan penggunaan Whatsapp dalam pembelajaran dapat meningkatkan kemampuan berpikir kritis dan memecahkan masalah siswa jika dipadukan dengan pembelajaran konvensonal, sehingga diskusi pembelajaran pun dirasa lebih efektif menggunakan aplikasi ini.(Hadi, 2017; Harianto \& Wiguna, 2020)

\section{METODE}

Berdasarkan analisis situasi dan penelusuran literatur, maka tim AbdiMas berinisiatif melakukan one day coaching clinic pemanfaatan aplikasi Whatsapp sebagai salah satu sarana untukmelakukan evaluasi pembelajaran siswa kepada guru-guru SIT Mush'ab bin Umair. Kegiatan dilakukan di dua lokasi, yaitu di masjid sekolah tempat para peserta mengikuti kegiatan dan di Laboratorium Komputer Fakultas Teknik Universitas Muhammadiyah Palembang tempat para narasumber melakukan presentasi secara online. sekedar memberikan contoh bagi para pembaca.

Tim AbdiMas dibagi dalam dua kelompok; 1) kelompok "lapangan” yang terdiri dari seorang mahasiswa dan satu orang dosen untuk melakukan pendampingan langsung kepada para peserta ; 2) kelompok "narasumber" 
yang terdiri dari dua orang presenter materi dan satu orang moderator. Kelompok kedua ini melakukan kegiatan secara online. Hal ini dikarenakan untuk mengurangi jumlah kerumunan mengingat pembatasan sosial akibat pandemi yang tengah berlangsung. Sekaligus untuk memperkenalkan kegiatan pengajaran dalam format online conference kepada para guru.(Harianto \& Wiguna, 2020)

Penyampaian materi dilakukan secara online melalui aplikasi Zoom Meeting dalam bentuk Power Point yang berisikan panduan tahapantahapan pembuatan ujian online berbasis Whatsapp. Para peserta melakukan praktek langsung dengan mengikuti panduan demi panduan yang disajikan melalui screen projector dengan didampingi oleh anggota tim yang berada langsung di lapangan untuk memastikan peserta kegiatan dapat mengikuti panduan yang diberikan tanpa kesulitan yang berarti.(Dewi, 2020),(Farid, 2012)

\section{HASIL DAN PEMBAHASAN}

Pengamatan awal terhadap calon peserta kegiatan dilakukan dalam bentuk diskusi melalui Grup Whatsapp. Hal ini dilakukan mengingat pandemi yang masih berlangsung sehingga para guru hanya berada di sekolah pada harihari tertentu saja. Dari hasil diskusi diketahui bahwa Whatsapp menjadi sarana satu-satunya yang digunakan untuk pembelajaran secara online. Diketahui juga bahwa para guru semuanya telah memiliki akun Google dan penggunaannya selama ini terbatas pada email dan download berbagai aplikasi di Google Play Store.

Penggunaan Whatsapp sebagai media ujian online membutuhkan aplikasi tambahan yang harus diinstal di ponsel, yaitu Whatsapp Auto Reply. Selain itu, pengguna juga wajib memiliki akun Gmail untuk dapat mengakses Google Sheet yang menjadi media pembuatan soal beserta jawaban dan scorenya. Link soal dalam bentuk Excel di Google Sheet akan disinkronkan dengan Whatsapp Auto Reply. Jadi aplikasi inilah yang menjadi jembatan penghubung antara WhatsApp dengan Google Sheet Tipe soal yang paling cocok menggunakan aplikasi ini adalah soal pilihan ganda dan essay singkat.

Para guru SIT Mush'ab binUmair sebagian besar telah memiliki arsip bank soal untuk kedua jenis soal tersebut. Sehingga dalam prakteknya, para peserta tinggal menyalin soal-soal yang sudah ada ke dalam Google Sheet dan menyusunnya sesuai dengan format yang disyaratkan oleh Whatsapp Auto Reply. Pada dasarnya untuk membuat soal ujian online berbasis Whatsapp yang terintegrasi dengan Google Sheet hanya membutuhkan dua kolom; kolom pertama berisikan pertanyaan dan kolom kedua berisikan jawaban atau auto response. Berikut adalah gambar aplikasi Whatsapp Auto Reply, Google Sheet yang telah berisi soal dan tampilan di Whatsapp.

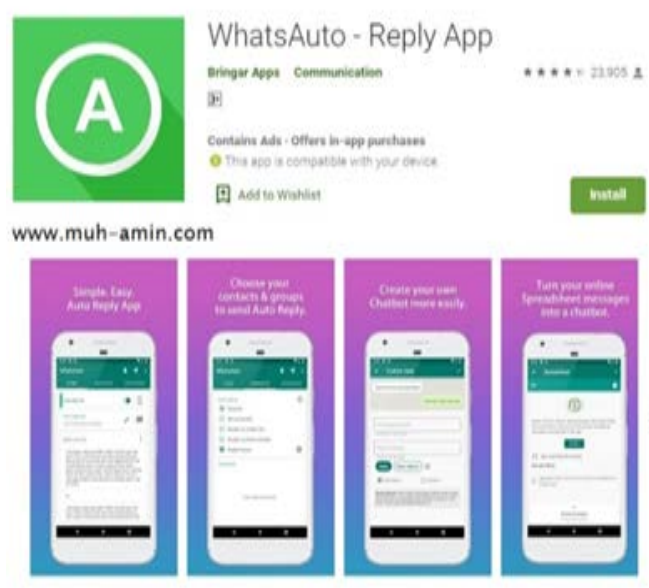

(a) Whatsapp Auto Reply 
Taufik Barlian. Aplikasi Whatsapp Sebagai Media Alternatif Ujian Online Di ...
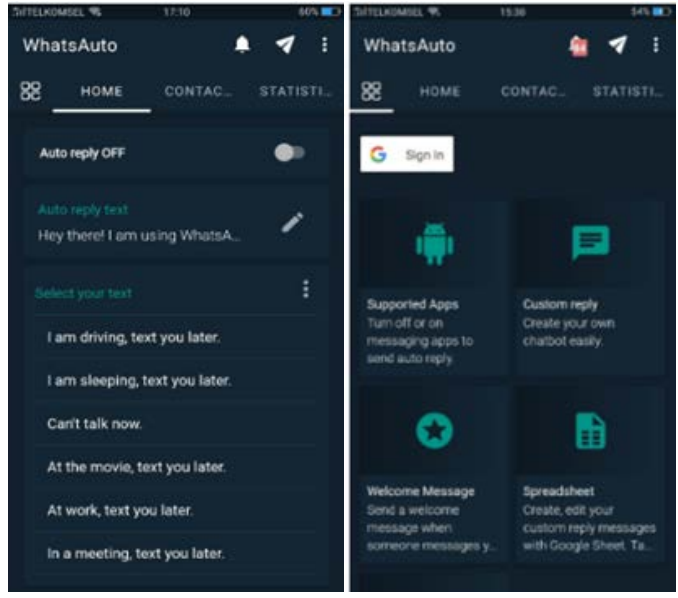

(b) Fitur-fitur pada Whatsapp Auto Reply

Gambar 1. Aplikasi Whatsapp Auto Reply

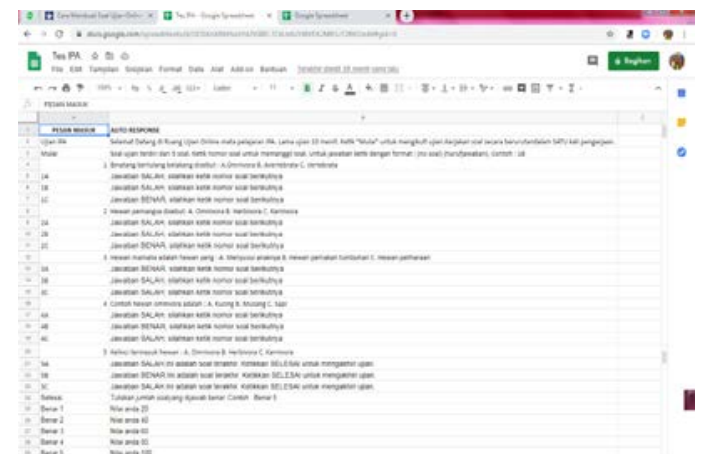

Gambar 2. Data soal , jawaban dan score pada Google Sheet

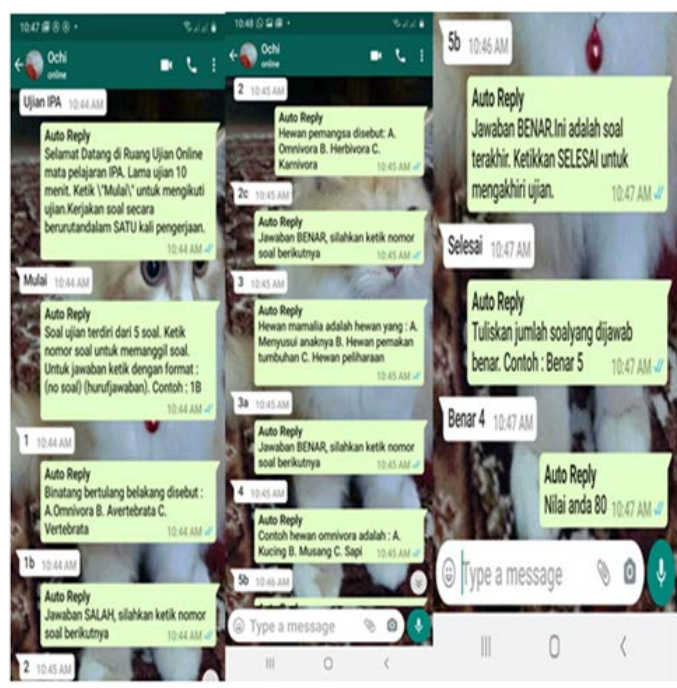

Gambar 3. Tampilan ujian online berbasis Whatsapp pada layar ponsel guru dan siswa
Respon para guru pada kegiatan ini amat baik. Terlihat dari keaktifan mereka dalam mengikuti tahap demi tahap pembuatan soal. Untuk melihat apakah sistem ujian online yang dibuat peserta berjalan dengan baik, maka setiap peserta secara berpasangan mempraktekkan sistem ini secara bergantian. Para guru antusiasdengan adanya kegiatan ini, karena aplikasi yang selama ini mereka pakai dapat digunakan sebagai media ujian online yang amat mudah penggunannya dan amat membantu guru dalam penilaian.

Disamping itu ujian online menggunakan Whatsapp ini dirasakan para guru sebagai salah satu sarana untuk menumbuhkan sikap jujur daripara siswa, karena sebagaimana yang ditunjukkan pada Gambar 3, siswa diharapkan kejujurannya untuk melaporkan jumlah soal yang benar dan score yang didapat kepada gurunya melalui fasilitas screen shoot. Karena tampilan di layarponsel guru dan siswa sama, maka Guru dapat mengetahui kebenaran laporan hasil ujian siswa.
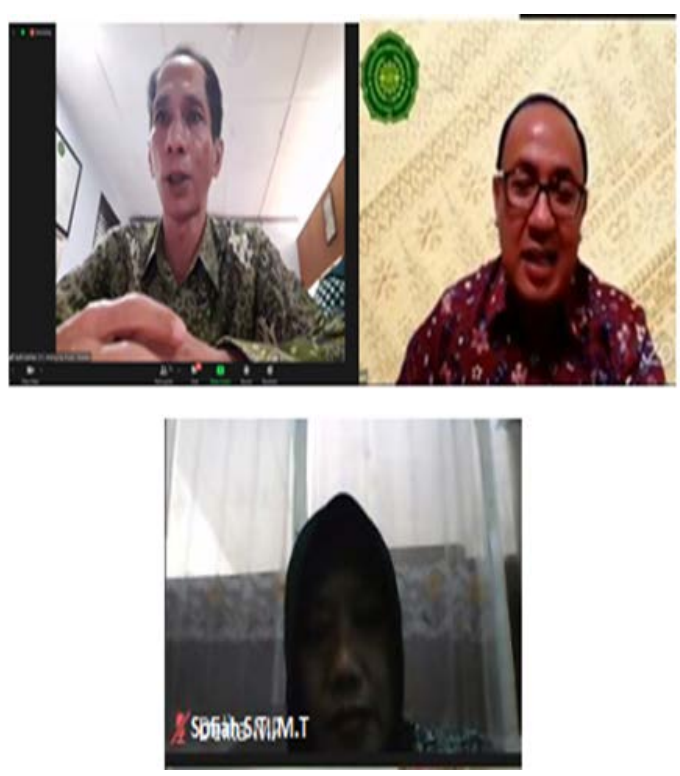

Gambar 4. Para Narasumber memberikan matreri secara virtual 


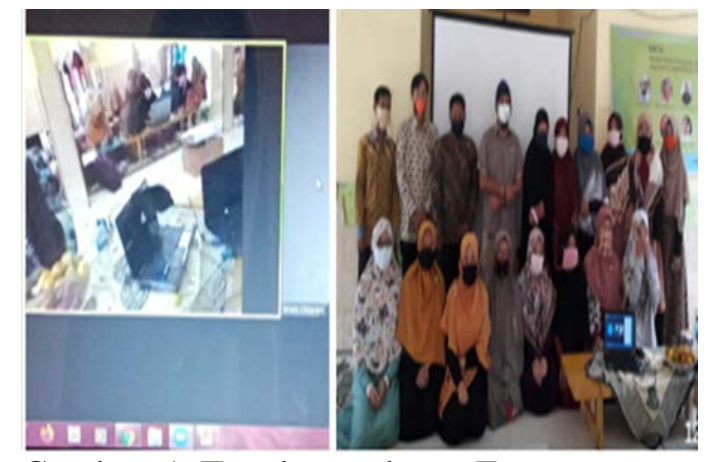

Gambar 5. Tangkapan layar Zoom suasana para peserta kegiatan (kiri) dan foto bersama setelah kegiatan (Kanan)

Dari kegiatan ini, para guru dapat mengetahui manfaat lain dari akun Gmail yang dimiliki, seperti akses ke Google Class Room, Google Form,Google Drive dan Google Meet yang semuanya dapat mendukung proses pembelajaran secara online di SIT Mush'ab bin Umair. Untuk itu akan direncanakan kegiatan yang sama dengan materi-materi tersebut. Tabel.1 menunjukkan indikator capaian kegiatan.

Tabel 1. Indikator Capaian Keberhasilan Kegiatan

\begin{tabular}{|c|c|c|}
\hline $\begin{array}{l}\text { Pengetahuan } \\
\text { Peserta }\end{array}$ & Pre-Kegiatan & $\begin{array}{c}\text { Post- } \\
\text { Kegiatan }\end{array}$ \\
\hline $\begin{array}{l}\text { Penggunaan } \\
\text { Whatsapp }\end{array}$ & $\begin{array}{l}\text { Informasi } \\
\text { materi } \\
\text { belajar, } \\
\text { pengumuman } \\
\text { yang } \\
\text { berkaitan } \\
\text { dengan } \\
\text { sekolah. }\end{array}$ & $\begin{array}{lr}\text { Dapat } & \text { digunakan } \\
\text { sebagai } & \text { sarana } \\
\text { ujian } & \text { dengan } \\
\text { format } & \text { yang } \\
\text { sederhana. } & \end{array}$ \\
\hline $\begin{array}{l}\text { Pembuatan } \\
\text { soal ujian }\end{array}$ & $\begin{array}{l}\text { Diketik dalam } \\
\text { file word lalu } \\
\text { dikinim ke } \\
\text { siswa melalui } \\
\text { WA. Siswa } \\
\text { menginimkan } \\
\text { jawaban } \\
\text { dalambentuk } \\
\text { foto juga } \\
\text { melalui WA. }\end{array}$ & $\begin{array}{l}\text { Soal } \\
\text { muncul secara } \\
\text { otomatis setelah } \\
\text { siswa } \\
\text { mengetikkan } \\
\text { kalimat perintah } \\
\text { tertentu. Jawaban } \\
\text { dan score muncul } \\
\text { otomatis sehngga } \\
\text { memudahkan guru } \\
\text { dalam pemberian } \\
\text { nilai. }\end{array}$ \\
\hline $\begin{array}{l}\text { Penggumaan } \\
\text { akun Gmail }\end{array}$ & $\begin{array}{l}\text { Akses email } \\
\text { dan aplikasi- } \\
\text { aplikasi } \\
\text { android }\end{array}$ & $\begin{array}{l}\text { Akses ke Google } \\
\text { Class } \\
\text { Google } \\
\text { Form, Google } \\
\text { Drive dan Google } \\
\text { Meet }\end{array}$ \\
\hline
\end{tabular}

\section{SIMPULAN}

Kegiatan ini dirasakan amat bermanfaat bagi para guru SIT Mush’ab bin Umair. Keterbatasan sarana dan prasarana pembelajaran online sebagian dapat teratasi dengan penggunaan Whatsapp. Penggunaan Whatsapp sebagai sarana ujian online dirasakan relatif murah dengan jangkauan yang luas, mudah dalam penggunaan terutama bagi sebagian besar siswa SIT Mush'ab bin Umair yang masih duduk di kelas 1 dan 2 .

Untuk lebih mendukung penyelenggaraan pembelajaran online, para guru SIT Musg'ab bin Umair perlu diberikan tambahan pengetahuan terkait dengan aplikasi-aplikasi Learning Management System lainnya seperti Google Class Room dan Google Form.

\section{DAFTAR PUSTAKA}

Dewi, W. A. F. (2020). Dampak COVID-19 terhadap Implementasi Pembelajaran Daring di Sekolah Dasar. Edukatif: Jurnal Ilmu Pendidikan, 2(1), 55-61. https://doi.org/10.31004/edukat if.v2i1.89

Farid, M. G. (2012). Analisis Dan Perancangan Sistem Ujian Online Di Smp Muhammadiyah 2 Godean.

Hadi, S. (2017). Efektivitas penggunaan video sebagai media pembelajaran untuk siswa sekolah dasar. Seminar Nasional Teknologi Pembelajaran Dan Pendidikan Dasar 2017, 96-102. Retrieved from

http://pasca.um.ac.id/conferenc es/index.php/sntepnpdas/article /view/849/521

Harianto, W., \& Wiguna, A. S. (2020). Pelatihan Corel Draw Untuk Perangkat Desa. 3, 1-4.

Kartikawati, S., \& Pratama, H. (2017). Pengaruh

Penggunaan 
Taufik Barlian. Aplikasi Whatsapp Sebagai Media Alternatif Ujian Online Di ...

WhatsApp Messenger Sebagai

Mobile Learning Terintegrasi

Metode Group Investigation

Terhadap Kemampuan

Berpikir Kritis. Jupiter (Jurnal

Pendidikan Teknik Elektro),

2(2),

33.

https://doi.org/10.25273/jupiter

.v2i2.1797

Sofyana, L., \& Rozaq, A. (2019).

Pembelajaran

Daring

Kombinasi Berbasis Whatsapp

Pada Kelas Karyawan Prodi

Teknik Informatika Universitas

Pgri Madiun. Jurnal Nasional

Pendidikan Teknik Informatika

(JANAPATI), $8(1), \quad 81$.

https://doi.org/10.23887/janapa

ti.v8i1.17204

Suana, W., Raviany, M., \& Sesunan, F.

(2019). Blended Learning

Berbantuan Whatsapp:

Pengaruhnya Terhadap

Kemampuan Berpikir Kritis

Dan Kemampuan Pemecahan

Masalah. Gravity: Jurnal

Ilmiah Penelitian Dan

Pembelajaran Fisika, 5(2), 37-

45.

https://doi.org/10.30870/gravit

y.v5i2.4990

Suryani, Y. E. (2010). Kesulitan belajar. Magistra, (73), 33-47. 